\title{
THE BASIC PRINCIPLES OF RESEARCH IN NEUROEDUCATION STUDIES
}

Dr. Ali Nouri, Assistant Professor in Curriculum Studies, Malayer University, Iran E-mail: alinooripo@gmail.com

\section{A R T I C L E I N F O}

Studies and Articles

Received: Ferburary, 20.2016.

Revised: April, 21.2016.

Accepted: April, 26.2016.

doi:10.5937/IJCRSEE1601059N

UDK

$165: 37$

$37: 616.8$

$159.95: 616.8$

Keywords:

neuroeducational research, research methodology, neuroeducation studies, principles of research.

\begin{abstract}
A B S T R A C T
The present paper assembles contributions from the areas of education, psychology, cognitive science, and of course, neuroeducation itself to introduce the basic principles of research in the field of neuroeducation studies. It is particularly important, as such it is a useful way to justify researchers about what neuroeducation as a specific domain do that no other field can do as well or cannot do at all. Based on the literature reviewed, neuroeducational research can be understood as an interdisciplinary endeavor to develop an insightful understanding and holistic picture of problems related to learning and education. It thus epistemologically is based on an integrated methodological pluralism paradigm. This requires researchers to understand multiple methods and methodologies and employ as they formulate their own research projects. Researchers have a critical role to play in providing systematic evidence and conclusions that are scientifically valid and reliable and educationally relevant and usable. One significant implication of this argument is the need to strengthen the quality of the research component in graduate programs of the field and train interested researchers in the identification and formulation of relevant research questions.
\end{abstract}

(C) 2016 IJCRSEE. All rights reserved.

\section{INTRODUCTION}

In recent decades, a growing number of educational researchers have shown an increasing interest in development a new science of learning that can potentially contribute to evidence-based policy and practice in education (e.g. Meltzoff et al., 2009; HowardJones, 2011a; Howard-Jones, 2010; Ansari, De Smedt and Grabner, 2012; Schwartz abd Gerlach, 2011; Geake, 2009 \& Campbell, 2011). Throughout of this paper, this newly emerging field is termed 'Neuroeducation Studies' and defined as a growing interdisciplinary field based on the synergetic connection between neuroscience, cognitive science, psychology, and education in an effort to improve our theo-

Corresponding Author

Dr. Ali Nouri, Assistant Professor in Curriculum

Studies, Malayer University, Iran

E-mail: alinooripo@gmail.com

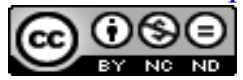

This work is licensed under a Creative Commons Attribution 4.0 International license. The article is published with Open Access at www.ijcrsee.com retical and practical understanding of learning and education (Nouri, 2013). Other terms have been used somewhat synonymously with neuroeducation studies including "Educational Neuroscience" and "Mind, Brain and Education". The term "neuroeducation" according to Howard -Jones (2011a), "better reflects a field with education at its core, uniquely characterized by its own methods and techniques, and which constructs knowledge based on experiential, social and biological evidence" (p. 29). The suffix "studies" is added to best feature its interdisciplinarity nature and distinguish it from single disciplines; as such it has been recruited by other interdisciplinary fields such as "Curriculum Studies", Cultural Studies", "Environmental Studies", "Law studies" and so on (Nouri, 2013).

Neuroeducation studies, however, should be completely distinguished from previous initiatives such as "brain-based learning" or "brain-based education" that were common just a few years ago. That kind of language according to Ron Brandt (2012) may have been useful "to get educators' attention, but it has quickly become outmoded" (p. 15). Brain - based education has been strongly 
criticized for promulgating misinterpreted, misconnected, oversimplified, and or overgeneralized conceptions regarding neuroscientific facts. For example, Bruer (1999) sarcastically criticized enthusiasts of brain-based learning in this way:

We can only be thankful that members of the medical profession are more careful in applying biological research to their professional practice than some educators are in applying brain research to theirs (p. 657).

Such misconceptions can lead to 'neuromyths' such as $10 \%$ use of the brain, VAK learning styles, left- and right-brain thinking, enriched environments, Brain Gym $\mathbb{C}$ method and critical periods. Indeed, none of such false claims are supported by current scientific and educational evidence (Bruer, 1999; OECD, 2002; Goswami, 2004).

Although neuromyths still persisted, the field of neuroeducation studies has experienced considerable progress over the two last decades. However, there is still much significant work to be done to stabilize and advance its disciplinary scope and boundaries. Some scholars in the field emphasize the need to address the issues and concerns pertaining to methodological considerations as one of the most promising and original ways to contribute to the further development of the field (Stein, and Fischer, 2011; Campbell, 2011). Paul Howard-Jones as the most enthusiastic scholar in the area of "neuroeducational research" has already begun to address such concerns (Howard-Jones, 2008; 2010; 2011a; $2011 \mathrm{~b}$ ). In order to significantly come up to problems of the school curriculum and pedagogy, Howard-Jones (2010) outlines the aims of neuroeducational research in two directions that are critically related to each other: to enrich and develop educational understanding and practice; and to further scientific understanding of behaviors associated with learning. He persuasively proposes a multiperspective approach to integrating three types of biological, social and experiential evidence. These evidence are provided by three forms of scientific, bridging and practice-based studies with own specific methods and techniques. Scientific studies focus on developing basic knowledge pertinent to educational concepts. Bridging studies investigate ways that knowledge can be used in more "real-world" educational contexts. And, practice-based studies translate these concepts into best practices that are transferable to educational practitioners.

Other leading scholars in the field, Stein and Fischer (2011) offer a useful conceptual framework for this discussion, identifying $a$ problem-focused methodological pluralism as an emergent mode of knowledge production which entails a kind of openness toward different methodological approaches and traditions. They argue that the validity of work in the field is ultimately determined by a kind of pragmatism which administrated by three criteria: scientifically valid, educationally relevant, and educationally effective. They also propose the establishment of "research schools" where practice and science jointly shape educational research (Stein and Fischer, 2011; Fischer, 2009).

Following the previous attempts, the present paper assembles contributions from the areas of education, psychology, cognitive science, and of course neuroeducation itself to provide an integrative and holistic understanding of the meaning and scope of research in the field. Specifically, this paper will introduce the basic principles of research in the field to open up a practical space for a constructive engagement with neuroeducational research. It could be argued that such a line of research is necessary as the basis for a common language with which we can begin to formulate interdisciplinary studies focused on educational issues. It is particularly important, as such it is a useful way to justify researchers what neuroeducation as a specific domain within education do that no other field can do as well or cannot do at all. To this end, the first section of paper dedicated to outlining a set of principles that should be considered in conducting scientific research in the field. The second section provides a working definition for neuroeducational research. And, the third section of paper ends with a conclusion and suggests some directions for further development of the field.

\section{A. THE PRINCIPLES OF RESEARCH: RESPONSIBILITIES FOR RESEARCH}

This section provides an overview of five methodological principles that influence research in neuroeducation. Simply put, by the term "research", here it is referred to any form of disciplined inquiry aiming to build a valid and reliable base of knowledge about a particular phenomenon through a set of systematic methods and techniques.

The principles need to be understood as a set of standards of inquiry that encourage neuroeducation researchers to think about 
the nature and purposes of research and the general expectations for conducting scientific research in the field. Collectively, insightful consideration of such principles is essential in order to ensure that conclusions drawn from research are scientifically valid and reliable and educationally relevance and usable.

\section{RESEARCH IN NEUROEDUCATION IS INTERDISCIPLINARY BASED}

This principle stands as the basic assumption underlying research in education that defines education as a complex social enterprise. From this point of view, educators need to be able to think about educational issues from a number of points of view. They ought to have enough of a familiarity with other relevant disciplines so that they can at least participate meaningfully when important issues are being addressed (Gardner, 2009). It is, therefore, important to recruit the insights from research in psychology, sociology, philosophy, biology and other contributory disciplines to the field of education. The diversity and different viewpoints from multiple disciplines and within disciplines foster a deeper understanding than viewpoints from one of them. As noted by Popper (1963), "we are not students of some subject matter, but students of problems. And problems may cut right across the borders of any subject matter or discipline." (p. 67).

There is a greater sense of urgency felt today come up with educational issues looking by multidimensional and multidisciplinary lenses. In this way, many educational problems can be solved by bringing together the knowledge and skills of a wide range of disciplinary experts (e.g. educators, philosophers, psychologists, sociologists, anthropologists, and neuroscientists). By this understanding, new opportunities for systematic collaboration between neuroscience, cognitive sciences and education have opened up in recent decades. Researchers working in the field of neuroeducation integrate these neural, psychological and pedagogical bases of learning and development to provide greater insight and understanding into the complexities of educational phenomena. They need to look through these sources of knowledge in order to understand clearly what should be studied? Why and how? Consequently, neuroeducation leaders frequently have cited the need for interaction among members of contributing fields. Re- searches in Neuroeducation hence need to design studies based on the theories and models of all contributing disciplines and integrate the expertise of multiple disciplines. This is what referred to interdisciplinary research,

"interdisciplinary research is a mode of research by teams or individuals that integrates information, data, techniques, tools, perspectives, concepts, and/or theories from two or more disciplines or bodies of specialized knowledge to advance fundamental understanding or to solve problems whose solutions are beyond the scope of a single discipline or area of research practice" (National Academy of Sciences, 2005, p. 2).

The potential of neuroeducation to succeed as a field according to Schwartz and Gerlach (2011) rests in its ability to generate new ways of understanding and solving educational problems by employing the perspectives of other disciplines such as (but not limited to) genetics or neuroscience. Those neuroeducators who understand multiple educational perspectives will be better able to formulate and design their own studies regarding educational issues and challenges. Nevertheless, there are few studies of educational issues conducted through collaborations between educators and scientists in the fields of neuroscience and cognitive science. As an example of such work is the study of fostering creativity (HowardJones, Winfield and Crimmins, 2008), a collaborative study has been done by an interdisciplinary team and a group of trainee teachers to co-construct concepts about the fostering of creativity thinking.

\section{RESEARCH IN NEUROEDUCATION IS PRACTICE BASED}

The demanding nature of educational research as applied is not new (Stein, and Fischer, 2011) and it is so central in historical thinking in educational research that it is almost a truism and hardly needs restatement. According to Dewey (1929).

Scientific findings are of practical utility, and the situation is wrongly interpreted when it is used to disparage the value of science in the art of education. What it militates against is the transformation of scientific findings into rules of action (p. 19).

In accordance with Dewey's views, Stein and Fischer (2011) have proposed two important goals for neuroeducational research; the first is to understand fundamental problems 
concerning the learning and teaching and the second is to utilize this understanding to investigate existing products and develop new ones that would potentially advance the quality of educational practice. They accordingly defend conducting research in the context of practice as the best way to sort out the complex interdisciplinary and epistemological issues surrounding differences between levels of analysis and basic viewpoints. It requires researchers to understand what and how teachers teach and which measurements are most useful and teachers to understand what research currently can deliver and how to frame the demands they make on it (Hardiman et al., 2009).

Neuroeducational research, therefore, needs to strategically focus on improving the curriculum and pedagogy; because the progress of the field is wedded to the progress of educational practices (Stein and Fischer, 2011). It should be focused on integrating research with practice to create useful evidence that illuminates the brain and genetic bases as well as social and cultural influences on learning and teaching (Fischer, et al, 2010). Bringing together scientists and educators in laboratory schools and other forums will encourage a joint solution to problems that neither domain could answer alone (Hardiman, 2009; Worden, et al, 2011). This means that teachers and researchers should be encouraged to involve more in action research so that they can identify and investigate relevant research questions and find possible applications to the classroom. At the same time, they should take into account the possible ways in which research findings may be used.

In the last two decades, much valuable work has been done to build knowledge that is more applicable to the classroom teaching. For example, based on the research on plasticity, Paula Tallal and his colleagues have developed a training software program called "FastForWord" in order to remedy the difficulty in learning to read in some children suffered from dyslexia due to an auditory processing delay in their brain. Since the brain is remarkably adaptive, this program makes it possible to speed up the processing of the sounds of the written word and improve reading skills. Despite the limitations, the effectiveness of the program has been demonstrated in several rigorous studies (Tallal et al., 1996). Inspired by cognitive neuroscience research, Wilson et al. (2006) also have developed "The Number Race" software that has been successful in remediation of dyscalculia. This computer- ized adaptive game has been designed based on current understanding of the cerebral representation of the number and the hypotheses that dyscalculia could be caused by a core deficit in number sense or in the links between this representation and learned symbolic representations of number.

There are therefore some examples of translating knowledge from basic research to educational application. At the same time, there are also many different commerciallyavailable treatment programs such as "Brain Gym" which are advertised as able to improve cognitive and academic performance. However, there is little or no evidence supporting the efficacy of such programs.

Altogether, there is needed to be cautious in direct translating basic scientific research into educational practice and policy. According to this view, the implementation of basic research results to solve practical problems is often very indirect and rarely straightforward (Ansari, Coch and De Smedt, 2011). Laboratory data need to be rigorously evaluated and carefully tested in a few classrooms before they applied too broadly (Brown and Bjorklund, 1998). It suggests the need for a new field of inquiry that is both scientifically and educationally grounded (Howard-Jones, 2011a).

\section{RESEARCH IN NEUROEDUCATON REQUIRES UNDERSTAND- ING AND EMPLOYING MULTIPLE METHODS AND METHODOLOGIES}

As mentioned earlier, neuroeducational research is interdisciplinary in nature. This suggests a selection of the ways in which the natural and social sciences can meet and support each other in neuroeducational research; a research area that attempts to develop both a scientific and educational understanding of learning (Howard-Jones, 2011b).

Although the theories, methods, instruments, and aims of qualitative and quantitative research differ, but there is no overarching reason to see them as inherently incommensurable (Campbell, 2011). One approach is superior to the other only with respect to the nature of the problem under investigation (Eisner, 1994). In this context, all research methods within quantitative and qualitative methodologies have the potential to uncover 
new levels of understanding of what goes on in schools. Put another way, no one of these approaches is better than any other. Employing both approaches is advantageous because it becomes possible to bumper the limitations of each approach and to bring out complementary strengths. Longitudinal studies such are of particular importance to the understanding of learning through the lifespan and qualitative methods can contribute to our understanding of mind, brain and education relations. Noninvasive neuroimaging techniques can also be used as a complementary way to uncovering the neural mechanisms underlying learning and development. According to Campbell (2010).

The validity, reliability, and relevance of theories of teaching and learning in education research may variously be corroborated, refined, or refuted through neuroscientific studies or the use of neuroscientific tools and methods to test hypotheses of any particular theoretical account (p. 319).

Indeed, answering questions dealing with complexities of learning and education requires adopting multiple and even inventing new research methodologies. Neuroeducational researchers should thus be open to utilizing converging evidence from diverse levels of explanation, such as a recent work on motivational processes that suggests several educational implications with regard to the generation, maintenance, and regulation of motivation to learn in the learning environment (Kim, 2013). Such line of investigation provides a scientific context within which to understand students' motivation and translate into educational practice.

\section{RESEARCH IN NEUROEDUCATION IS CLOSELY ASSOCIATED WITH PHILOSOPHICAL ASSUMPTIONS}

Education is an applied field closely related to the philosophy and the key concepts in the field are philosophical in nature. It is the philosophical orientation that determines the aims of education and what should be taught. In the context of research methodology, these relate to differences in ontological and epistemological assumptions. There are different kinds of philosophical orientations and each of them reflects a unique ontological/epistemological viewpoint- what is called research paradigm. A paradigm is a lens of looking at the world. It is composed of certain philosophical assumptions that influence what should be studied, how research should be done, and how results should be interpreted (Bryman, 1988; Mertens, 2005). Depending on their philosophical orientation and related ontological and epistemological assumptions, researchers will be asking different sets of questions about the nature of an educational phenomenon which consequently lead to employing different methodologies and procedures. Research in education can be broadly categorized into five major paradigms- positivism, post-positivism, constructivism, transformative, and pragmatic (Mertens, 2005). Although article space does not permit expansion on these paradigms, the main point is that each paradigm has grounded in fundamentally different assumptions which impose different methodological considerations. Sufficed to say, researchers within each paradigm have their own perceived appropriate philosophical perspectives. However, as Campbell (2011) stated, "it is not necessary for educational neuroscientists of various ilks and inclinations to hold identical philosophical views regarding these matters, but ... it does behoove researchers in this area to be open and clear about where they stand on them" (p. 8).

Researchers, therefore, should be able to identify the worldview that most closely approximate their own and guide their thinking and practice (Mertens, 2005). From this point of view, neuroeducational researchers must be aware of methodological assumptions on which they rely and ultimately, be able to openly reflect on and distinguish their own orientation from that of others.

\section{RESEARCH IN NEUROEDUCATION IS VALUE SATURATED}

As neuroeducators need to understand the philosophical basis of research in education, they also need to understand the moral and ethical aspects of educational policies that policymakers may make based on the results of their research. It is broadly accepted that education is above all a value-laden profession, with its values in perpetual dispute. More so than most other professionals, educators experience competing demands from many stakeholders along with considerably less autonomy and status (Sheridan, Zinchenko, and Gardner, 2006). Indeed, medicine, law, accounting, engineering, and architec- 
ture all involve value judgments; however, the core values of these professions are not particularly controversial. In contrast, education is driven by fundamental questions of value on which nearly all citizens have strong and often inconsistent opinions (Gardner, 2009). For example, unlike medicine, which aims at promoting health, education promotes values that reflect the kind of citizen and ultimately the kind of society we aspire to create (Ferrari, 2011). Educational research like other forms of educational activity thus is politically driven and value saturated. For educators, the process of research mainly influenced by ethical questions of what should be taught for what ends or reasons (Yang, 2001; Nixon and Carr, 2003)

While ethical dilemmas in educational research are not new, what makes neuroeducation special is an advance in neurocognitive tools that pose unique ethical challenges. The prevalence of neuromyths could be considered as one of the negative results of such advances which have both educational and ethical implications (Sheridan, Zinchenko, and Gardner, 2006). Neuroeducation researchers have a significant role to play in preventing and debunking these prevalent myths that are not supported by sound empirical data. Researchers, therefore, have a serious obligation to involve in translating research findings into educational applications and producing new knowledge that will contribute to the improvement of educational policy and practice. Such involvement will help policy makers to make informed decisions based on the results of their studies.

Education as mentioned, according to its conception functions and values is a moral enterprise, and educators must not only consider what scientific studies can provide, but they must also evaluate the results and applications of those studies on existing social, ethical, and legal structures (Roskies, 2002; Zambo, 2013). The new area of educational neuroeth$i c s$ has arisen in response to such ethical issues and challenges (Zocchi and Pollack, 2013; Hardiman, Rinne, Gregory and Yarmolinskaya, 2012; Lalancette and Campbell, 2012).

In this context, educational theorists, researchers, and practitioners alike have a leading role to play in the ethical issues involved in applying neuroscience research to educational practice. Neuroeducational researchers must consider ethical matters in the treatment of research participants, conducting the research and reporting research findings. They should understand that educational phenomena are strongly tied to policy and practice and need to be aware of the value-laden nature of educational decisions and policies. Furthermore, the rationale, method, analysis, results, and conclusions of the study need to be presented clearly. The method of research should also be chosen with respect to the question being asked and be related to the specific goal of the study.

\section{B. THE OPERATIONAL CONCEPTION OF NEUROEDUCATIONAL RESEARCH}

In the last section, the prominent aspects of neuroeducational research were reviewed and outlined into five principles. In this section, a definition is presented that integrates the core concepts embedded in those principles. A common definition will help the field achieve greater depth and sophistication about the meaningful assessment of current brainbased claims and will facilitate collaboration amongst researchers from different disciplines. From this understanding, it is possible to offer an integrated definition of neuroeducational research:

Neuroeducational research is an interdisciplinary endeavor to develop an insightful understanding and holistic picture of problems related to learning and education. It thus epistemologically is based on an integrated methodological pluralism paradigm. This requires researchers to understand multiple methods and methodologies and employ as they formulate their own research projects. Researchers have a critical role to play in providing systematic evidence and conclusions that are $s c i$ entifically valid and reliable and educationally relevant and usable.

It should be mentioned that this definition is consistent with the conceptualization that a group of experts in the field agreed about in a recent study aimed to define the boundaries of neuroeducation as a field of study (See Nouri and Mehrmohammadi, 2012).

\section{CONCLUSION REMARKS}

While all science shares a set of underlying principles of inquiry, the kinds of research questions and the nature of evidence in neuroeducation are partly unlike the kinds of questions and evidence that psychologists and neuroscientists or even educators might expect. 
To take up this challenge, we will have to borrow methods and tools from all contributing fields, and, at the same time, we will undoubtedly have to invent new ones. Noteworthy, Pincham, et al., (2014) have developed a fourstage practical approach that views the educational neuroscientist as a dual research scientist, who is cognisant with neuroscientific and educational research techniques. At the first stage, researchers and teachers work together to identify an educational need that educational neuroscience has the potential to help answer. During the second stage, the educational neuroscientist develops a research proposal that translates or assesses neuroscientific findings within educational settings. Following then, the educational neuroscientist empirically assesses whether findings derived from the laboratory can be used to improve educational practice or student outcomes. The final step in this process requires collaborative reflection to evaluate the research findings.

The establishment of a new area of neuroeducational research, however, should not be viewed as a panacea for all the pressures facing education and the ethical dilemmas posed by scientific advances; it may even create additional ethical challenges. Neuroeducation researchers need to be fully subject to the safeguards guiding the medical professions and research on human subjects (particularly children), and also responsible for a review system that safeguards educational values (Sheridan, Zinchenko, and Gardner, 2006). Effective neuroeducational research, therefore, requires educators to play a central role along with researchers in formulating questions and methods (Fischer, et al, 2010).

One significant implication of this argument is the need to strengthen the quality of the research component in graduate programs of the field. There must be a group of scholars capable of practicing effectively in the field and advancing it. These professionals will need to achieve the ability to plan, design and carry out a research in the domain of neuroeducation and to widen the knowledge of theories regarding cognitive, affective, social and cultural foundations of education (Sylvan and Christodoulou, 2010).

Taken together, neuroeducational research is a complex and dynamic process in which many considerations and issues should be addressed. The above-presented body of principles may assist researchers in the identification and formulation of more relevant research questions. It also provides a useful framework based on which the quality of cur- rent research could be judged. Future attempts could be directed to clarify the link between methodology, methods and ethics of research in neuroeducation studies.

\section{ACKNOWLEDGMENTS}

I am most grateful to Dr. Bert De Smedt from the University of Leuven for his thoughtful comments and valuable feedback on the final version of the paper.

\section{Conflict of interests}

The author declare no conflict of interest.

\section{REFERENCES}

Ansari, D., Coch, D., \& De_Smedt, B. (2011). Connecting Education and Cognitive Neuroscience: Where will the journey take us. Educational Philosophy and Theory, 43(1), 37-42.

Ansari, D., De_Smedt, B., \& Grabner, R. H. (2012). Neuroeducation-a critical overview of an emerging field. Neuroethics, 5(2), 105-117.

Battro, A. M. (2010). The teaching brain. Mind, Brain, and Education, 4(1), 28-33.

Brandt, R. (2012). How educational neuroscience will contribute to 21 st century education. Creating an appropriate 21 st century education. Information Age Education (pp. Eugene, Oregon, USA.

Brown, R. D., \& Bjorklund, D. F. (1998). The biologizing of cognition, development, and education: approach with cautious enthusiasm.Educational. Psychology Review, 10(3), 355-373.

Bruer, J. T. (1999). In search of... brain-based education. Phi Delta Kappan, 80(9), 648-657.

Bryman, A. (1988). Quantity and quality in social research. London: London: Allen \& Unwin.

Campbell, S. R. (2010). Embodied minds and dancing brains: New opportunities for research in mathematics education. In Theories of mathematics education (pp. 309-331). Springer Berlin Heidelberg.

Campbell, S. R. (2011). Educational Neuroscience: Motivations, methodology, and implications.Educational Philosophy and Theory, 43(1), 7-16.

Dewey, J. (1929). The sources of a science of education. New York: Liveright Publishing Corp.

Eisner, E. (1994). The educational imagination: On the design and evaluation of school Programs. New York: Macmillan Publishing Company.

Ferrari, M. (2011). What Can Neuroscience Bring to Education. Educational Philosophy and Theo$r y, 43(1), 31-36$

Fischer, K. W. (2009). Mind, Brain, and Education: Building a Scientific Groundwork for Learning and. Teaching1. Mind, Brain, and Education, 3(1), 3-16.

Fischer, K. W., Goswami, U., \& Geake, J. (2010). The future of educational neuroscience. Mind, Brain, and Education, 4(2), 68-80.

Gardner, H. (2009). An education grounded in biology: Interdisciplinary and ethical considerations. Mind, Brain, and Education, 3(2), 68-73.

Geake, J. (2011). Position statement on motivations, 
methodologies, and practical implications of educational neuroscience research: fMRI studies of the neural correlates of creative intelligence. $E d$ ucational philosophy and theory, 43(1), 43-47.

Goswami, U. (2004). Neuroscience and education. British Journal of Educational Psychology,74(1), $1-14$.

Hardiman, M., Rinne, L., Gregory, E., \& Yarmolinskaya, J. (2012). Neuroethics, neuroeducation, and classroom teaching: Where the brain sciences meet pedagogy. Neuroethics, 5(2), 135-143. doi:10.1007/s12152-011-9116-6

Hardiman, M., Magsamen, S., McKhann, G., \& Eilber, J. (2009). Neuroeducation: Learning, arts, and the brain. New York/Washington, DC: Dana.

Howard-Jones, P. A. (2011a). A multiperspective approach to neuroeducational research.Educational Philosophy and Theory, 43(1), 24-30.

Howard-Jones, P. (2010). Introducing Neuroeducational Research. Abingdon, Routledge.

Howard-Jones, P. A. (2011b). From brain scan to lesson plan. Psychologist, 24(2), 110-113.

Howard-Jones, P. A., Winfield, M., \& Crimmins, G. (2008). Co-constructing an understanding of creativity in drama education that draws on neuropsychological concepts. Educational Research, 50(2), 187-201.

Howard-Jones, P. A., \& Fenton, K. D. (2012). The need for interdisciplinary dialogue in developing ethical approaches to neuroeducational research. Neuroethics, 5(2), 119-134.

Kim, S. (2013). Neuroscientific model of motivational process. Frontiers in Psychology, 4(1), doi: 10.3389/fpsyg.2013.00098

Lalancette, H., \& Campbell, S. R. (2012). Educational Neuroscience: Neuroethical Considerations. International Journal of Environmental and Science Education, 7(1), 37-52.

Meltzoff, A. N., Kuhl, P. K., Movellan, J., \& Sejnowski, T. J. (2009). Foundations for a new science of learning. Science, 325(5938), 284-288.

Mertens, D. M. (2005). Research and evaluation in education and psychology (2nd ed). Sage Publications: Thousand Oaks. London, New Delhi: Sage Publications: Thousand Oaks.

Sciences, A.o. (National), (2005). Facilitating interdisciplinary research. National Academies of Science, National Academy of Engineering, and Institute of Medicine of the National Academies. Washington DC: The National Academies: Press.

Nixon, J., \& Carr, W. (2003). The moral foundations of

Nouri, A., \& Mehrmohammadi, M. (2012). Defining the Boundaries for Neuroeducation as a Field of Study. Educational Research Journal, 27(1).

Nouri, A. (2013). Practical Strategies for Enhancing Interdisciplinary Collaboration in Neuroeducational Studies. International Journal of Cognitive Research in science, engineering and education (IJCRSEE), 1(2), 94-100.

Organisation for Economic Co-operation and Development. (2002).Understanding the brain: Towards a new learning science: OECD Publishing.

Pincham, H. L., Matejko, A. A., Obersteiner, A., Killikelly, C., Abrahao, K. P., \& Benavides-Varela, S. (2014). Forging a new path for educational neuroscience: an international young-researcher perspective on combining neuroscience and educational practices. Trends in Neuroscience and Education, 3(1), 28-31.

Popper, K. R. (1963). Conjectures and refutations: The growth of scientific knowledge. New York: Routledge and Kegan Paul.

Roskies, A. (2002). Neuroethics for the new millenium. Neuron, 35(1), 21-23.

Sanders, D. P. (1981). Educational inquiry as developmental research.Educational. Researcher,10(3), $8-13$.

Schwartz, M., \& Gerlach, J. (2011). The Birth of a Field and the Rebirth of the Laboratory School. Educational Philosophy and Theory, 43(1), 67-74.

Sikes, P., Nixon, J., \& Carr, W. (2003). The moral foundations of educational research: knowledge, inquiry and values. McGraw-Hill Education (UK).

Sheridan, K., Zinchenko, E., Illes, G. H., \& J, (2006). Neuroethics in education, in Neuroethics: Defining the issues in theory, practice, and policy. USA: Oxford University Press.

Stein, Z., \& Fischer, K. W. (2011). Directions for mind, brain, and education: Methods, models, and morality. Educational Philosophy and Theo$r y, 43(1), 56-66$.

Sylvan, L. J., \& Christodoulou, J. A. (2010). Understanding the role of neuroscience in brain based products: A guide for educators and consumers. Mind. Brain, and Education, 4(1), 1-7.

Tallal, P., Miller, S. L., Bedi, G., Byma, G., Wang, X., Nagarajan, S. S., ... \& Merzenich, M. M. (1996). Language comprehension in language-learning impaired children improved with acoustically modified speech. Science, 271(5245), 81-84.

Wilson, A. J., Dehaene, S., Pinel, P., Revkin, S. K., Cohen, L., \& Cohen, D. (2006). Principles underlying the design of "The Number Race", an adaptive computer game for remediation of dyscalculia. Behavioral and Brain Functions, 2(19), 1-14.

Worden, J. M., Hinton, C., \& Fischer, K. W. (2011). What Does the Brain Have to Do with Learning. What Does the Brain Have to Do with Learning?. Phi Delta Kappan, 92(8), 8-13.

Yang, O. S. (2001). An epistemological and ethical categorization of perspectives on early childhood curriculum. International Journal of Early Childhood, 33(1), 1-8.

Zambo, D. (2013). The Practical and Ethical Concerns of Using Neuroscience to Teach Young Children and Help Them Self-Regulate. In Early Childhood and Neuroscience-Links to Development and Learning (pp. 7-21). Springer Netherlands.

Zocchi, M., \& Pollack, C. (2013). Educational neuroethics: A contribution from empirical research. Mind, Brain, and Education, 7(1), 56-62. 